ARTICLE OPEN

\title{
Toxicity evaluation of an essential oil mixture from the Cretan herbs thyme, Greek sage and Cretan dittany
}

\author{
Konstantina Kalyvianaki $\mathbb{D}^{1}$, Panagiotis Malamos $\mathbb{( D}^{1}$, Niki Mastrodimou $\mathbb{( D}^{2}$, loanna Manoura-Zonou $\mathbb{D}^{1}$, Rodanthi Vamvoukaki $\mathbb{D}^{1}$, \\ George Notas', Niki Malliaraki $\mathbb{D}^{3}$, Eleni Moustou ${ }^{4}$, Maria Tzardi ${ }^{4}$, Stergios Pirintsos $\mathbb{1}^{5,6}$, Christos Lionis ${ }^{7}$, George Sourvinos ${ }^{8}$,

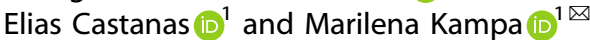

The importance of herbal extracts on health, which was initially based on ethnopharmacological and traditional knowledge, becomes increasingly well documented by numerous experimental and intervention studies. The daily use of beverages from different aromatic plants which becomes more popular nowadays, has been a tradition in Crete, and a habit that has been linked to the longevity seen in the island. Additionally, a certain combination of aromatic plants has been used against common cold and influenza. Interestingly, when such a mixture of essential oils from Cretan herbs (Cretan Aromatic Plants essential oil, CAPeo, from thyme, Greek sage, and Cretan dittany) was formulated, significant antiviral properties were observed in vitro and a significant reduction in the duration and severity of symptoms of patients with upper respiratory tract infections was found in a clinical study. However, since many plants extracts can exert toxic effects, toxicity issues should be properly addressed. In the present work we present an acute and sub-chronic toxicity evaluation for this mixture of aromatic plants' essential oils in rats. In fact, it is the only toxicity study for Cretan dittany. We report absence of toxicity, rendering the use of the mixture of essential oils from Cretan dittany, Greek sage and thyme as safe.

npj Science of Food (2020)4:20 ; https://doi.org/10.1038/s41538-020-00080-1

\section{INTRODUCTION}

Extensive research, in recent years, has revealed the pivotal role of oxidative stress in several chronic diseases, such as diabetes, cardiovascular, autoimmune, neurodegenerative and cancer, and the importance of antioxidants, including polyphenols. As a result, there is a great interest in natural antioxidative compounds which are widely found in plant material. Herbal beverages, being an important source for such compounds, such as polyphenols, which possess antioxidant, antiviral, and anti-inflammatory activities $^{1-3}$, have gained popularity among health-conscious consumers.

The daily use of beverages from different aromatic plants has been a tradition of Mediterranean and Southeastern populations, including Cretans. In fact, the longevity that was observed in the island of Crete (Salehi ${ }^{4}$ and references herein) can be partially attributed to the use of herbal extracts. This assumption guided a laboratory research certain years $\mathrm{ago}^{5}$, after an observational research that addressed morbidity and mortality data from a rural population in Crete $e^{6,7}$. Moreover, there were evidence pointing out that certain combinations of different aromatic plants of Crete could be beneficial for the prevention and cure of the common cold and influenza ${ }^{5}$. Based on these, our group recently has formulated a mixture of essential oils from three aromatic plants of Crete, thyme or Spanish oregano (Thymbra capitata (L.) Cav.), dictamnus or Cretan dittany (Origanum dictamnus L.,) and Greek sage (Salvia fruticosa Mill.; Cretan Aromatic Plants essential oil, CAPeo). We performed an in vitro study that verified the antiviral potential of CAPeo against a wide range of upper respiratory tract viruses. Our results showed that CAPeo had a remarkable antiviral activity against influenza $\mathrm{A} / \mathrm{H} 1 \mathrm{~N} 1$ virus strains, influenza $B$, and human rhinovirus 14 (HRV14), mainly due to defective trafficking of influenza A Nucleoprotein ${ }^{8}$. Additionally, in a double-blind randomized controlled trial, where CAPeo was administered to human subjects at doses corresponding to the consumption of 2-3 cups of beverage per day, confirmed that CAPeo decreases symptoms duration and severity, as well as systemic inflammation, as assayed by C-reactive protein [CRP] levels $s^{9,10}$, in patients with upper respiratory tract infections, with an apparent absence of toxicity, after the recommended 1-week consumption. Having in mind that certain herbal essential oils may have toxic effects, and that there are limited data concerning the toxicity of the used aromatic plant essential oils as a mixture, a thorough investigation of in vivo toxicity was essential, in spite of the lack of evidence for toxicity in humans ${ }^{9}$. Apparently, no such data were available for CAPeo, while there were only few reports for only two out of the three aromatic plants used in CAPeo, separately. Thyme essential oil, as well as some of its major constituents such as thymol and carvacrol has been the most studied. However, the majority of studies have examined Thymus vulgaris and not Coridothymus capitatus that is included in CAPeo (see Salehi et al. ${ }^{11}$ for a review, and Rojas-Armas et al. ${ }^{12}$ ). Nevertheless, it was found that Thymus vulgaris essential oil is less toxic than its essential constituent thymol. As reported by EFSA ${ }^{13}$ thymol has a moderate acute oral toxicity and high doses should be avoided ( $\left.\operatorname{LD}_{50} 1000 \mathrm{mg} / \mathrm{kg} \mathrm{bw}\right)^{12}$. As far as Greek sage (Salvia fruticosa) is concerned no data are available. There are few data only for Salvia officinalis reporting unwanted effects such as salivation, vomiting, tachycardia, and vertigo only after prolonged use and in overdose cases (ethanolic

\footnotetext{
${ }^{1}$ Laboratory of Experimental Endocrinology, School of Medicine, University of Crete, Heraklion, Greece. ${ }^{2}$ Laboratory of Pharmacology, School of Medicine, University of Crete, Heraklion, Greece. ${ }^{3}$ Laboratory of Clinical Chemistry and Biochemistry, University Hospital of Heraklion, Crete, Greece. ${ }^{4}$ Laboratory of Pathology, School of Medicine, University of Crete, Heraklion, Greece. ${ }^{5}$ Department of Biology, University of Crete, 71409 Heraklion, Greece. ${ }^{6}$ Botanical Garden, University of Crete, 74100 Rethymnon, Greece. ${ }^{7}$ Clinic of Social and Family Medicine, School of Medicine, University of Crete, Heraklion, Greece. ${ }^{8}$ Laboratory of Clinical Virology, School of Medicine, University of Crete, Heraklion, Crete, Greece. 凶email: kampam@uoc.gr
} 
extract or oil corresponding to more than $15 \mathrm{~g}$ of the leaves) ${ }^{14}$, and demonstrating a slight oral acute toxicity in rats ${ }^{15}$. Finally, no toxicity studies are available for dittany.

Therefore, the aim of the present work was to evaluate acute and sub-chronic toxicity of the essential oils from the three aforementioned aromatic plants, as a mixture (CAPeo), in a rat model. Different doses (at the range that CAPeo is effective, as an antiviral agent and we have previously used in the clinical study ${ }^{9}$ ) were tested by assaying several biochemical markers and histological analysis of selected organs for signs of necrosis, injury, or inflammation. Our findings clearly show that CAPeo does not induce any kind of toxicity in its either short- or long-term administration, even after administration of $20 x$ the suggested dose for humans.

\section{RESULTS}

Acute toxicity study

During the $24 \mathrm{~h}$ and 15 days of intervention there were no visible signs of toxicity (such as tremors, numbness, salivation, or diarrhea). All animals survived and no behavioral changes were observed.

All hematological and biochemical markers assayed (at the different time points and at the end of $24 \mathrm{~h}$ period) in all animals treated with CAPeo were not modified compared to their values at time point zero and to only oil treated animals. Especially as it is shown in Fig. 1a none of the CAPeo doses, administered to the animals (both males and females) for $24 \mathrm{~h}$, modified significantly the levels of the biochemical markers of liver and kidney toxicity (AST, ALT, creatinine, and urea), or the ratio of neutrophils/ lymphocytes (N/L) calculated as a marker of inflammatory response. The increase in hepatic enzymes observed in female animals at the dose of $10 \mathrm{X}$ was not considered significant, as it was not confirmed in the higher dose (40X). Similarly, no modifications of the biochemical markers of liver and kidney toxicity were observed 15 days after the highest dose was given (Fig. 2). These findings indicate the absence of an acute hepato- or nephrotoxicity. On the other hand, it was found that CAPeo decreased the $N / L$ ratio (Figs. $1 b$ and $2 b$ ), pointing out a possible anti-inflammatory action. Interestingly, the later effect was only observed after $24 \mathrm{~h}$ (Fig. 2b) and only in males suggesting a sexrelated effect.

In a macroscopic organ examination no detectable changes have been observed in the most important organs kidney, liver, lungs, and heart of the animals in all study groups at $24 \mathrm{~h}$ or 15 days. All organs examined appeared normal.

Finally, acute toxicity was also assessed using hematoxylin-eosin staining in formalin-fixed paraffin-embedded sections of selected tissues (kidney, liver, lungs, and heart) for all study groups. In all doses and times tested, no signs of toxicity were observed in all the organs examined after $24 \mathrm{~h}$. More specifically as it is shown in Fig. 3 (presenting tissues sections from animals treated with the highest dose at $24 \mathrm{~h}$, as an example) no necrotic areas or any other signs of liver, kidney, lung or heart injury or inflammation were observed.

\section{Sub-chronic Toxicity Study}

During the 16 weeks of the intervention, no mortality was observed, and the growth of the animals in all study groups was normal. Food intake was higher (almost double) in males than females, also reflected in their different growth rate, but no significant variations between the untreated animals, and those treated with the different doses of CAPeo were observed (Fig. 4a).

No salivation or diarrhea was noticed, and urine color was normal. Similarly, there were no changes in their skin, hair or eyes. Finally, no behavioral changes according to Irwin test or changes in food consumption and drinking activity were observed.
Several hematological and biochemical markers were assayed at the beginning and at the end of the study. During the four months of the intervention, no significant changes were observed between the different study groups. Similarly, to the acute study, neither the levels of biochemical markers of liver and kidney toxicity (AST, ALT, creatinine, and urea) nor the neutrophils/ lymphocytes (N/L) ratio, being a marker of inflammation (Fig. 4), were significantly modified by any CAPeo dose, both in male and female animals. These findings indicate the absence of any subchronic hepato- or nephrotoxicity. Interestingly, as far as the N/L ratio is concerned, the decrease that was observed in male animals after 24 hours in the acute study it was also observed after 4 months of treatment (Fig. 4c) and only in male animals. This effect was also persistent even when findings were corrected for the differences in food consumption or growth rate between males and females.

Examination of the organs, after 4 months of daily treatment of the animals, none of the CAPeo doses induced any detectable organ changes. All organs examined had a normal size and no macroscopical alterations were noticed.

Hematoxylin-eosin staining of tissue sections of all organs examined did not reveal any signs of toxicity. More specifically as it is shown in Fig. 5 no necrotic or inflammatory areas or any other signs of liver, kidney, lung or heart injury were evidenced. Minimal signs of inflammation were observed in the kidneys of all animals, independently of the administration of the essential oils or not, which might be attributed to the hosting conditions. Therefore, we conclude that the long-term administration of the essential oils was safe, and this reflects the absence of biochemical toxicity, as described above.

\section{DISCUSSION}

Nowadays, the quest for new, more effective, and safer therapeutic remedies resulted in incorporating the ethnopharmacological and traditional knowledge and exploring the usage of several plant and herbal extracts. As a result, many therapeutic agents have been developed. Under this scope, CAPeo (Cretan Aromatic Plants essential oil) was formulated, taking advantage of previous observational studies of our group ${ }^{5}$, exhibiting significant antiviral properties and reducing the duration and severity of symptoms of upper respiratory tract infections ${ }^{9,10}$. However, since many plants can exert toxic effects, the assumption that a composition is safe because it is natural, needs careful consideration, as, in many cases, adverse reactions may occur if inappropriately used. This necessitates, along with in vitro and clinical studies, in order to confirm their efficacy, proper toxicity studies for safety validation. It should be noted that toxicity evaluation of an essential oil mixture with a specific composition is slightly different to the testing of one essential oil or a chemical, since very high doses cannot be administered in order to obtain a median lethal dose $\left(\mathrm{LD}_{50}\right)$.

CAPeo is a mixture of essential oils of three different aromatic plants. For each of them there are either no adequate toxicity data available, such as for dittany, or the existing data discuss different species, as in the case of sage and thyme. Nevertheless, it was reported that Thymus vulgaris has an $\mathrm{LD}_{50}$ of $2840 \mathrm{mg} / \mathrm{kg} \mathrm{bw}^{16}$ or $1000 \mathrm{mg} / \mathrm{Kg} \mathrm{bw}^{12}$, which classifies it as moderately or slightly toxic (category $4 \quad\left(\mathrm{LD}_{50}: \quad 300-2,000 \mathrm{mg} / \mathrm{kg} \mathrm{bw}\right)$, or $5 \quad\left(\mathrm{LD}_{50}\right.$ : $2,000-5,000 \mathrm{mg} / \mathrm{kg} \mathrm{bw}$ ) respectively, in accordance with the Globally Harmonized Classification System (GHS) established by the OECD). Similarly, for sage, data are only available for Salvia officinalis and not for Salvia fruticosa that was included in CAPeo. The $\mathrm{LD}_{50}$ of $\mathrm{S}$. officinalis oil (when consumed orally) was $2600 \mathrm{mg} /$ $\mathrm{Kg} \mathrm{bw}^{17}$ classifying it as slightly toxic. There are also evidences for the major constituents of thyme, thymol and carvacrol. It seems that carvacrol is not toxic ${ }^{18}$, while thymol is moderately toxic $^{11,13,16}$. Considering the major constituents of CAPeo (as 

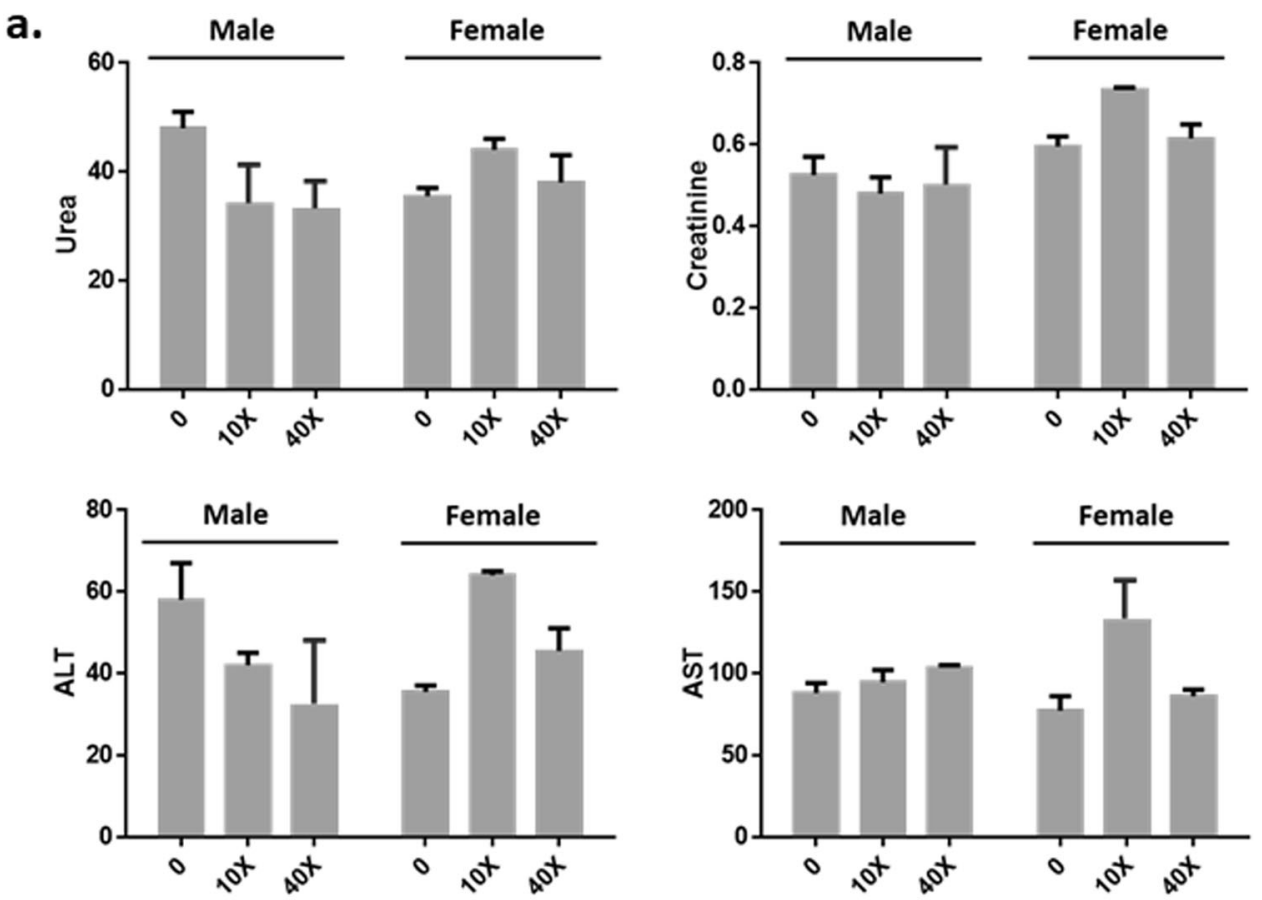

b.

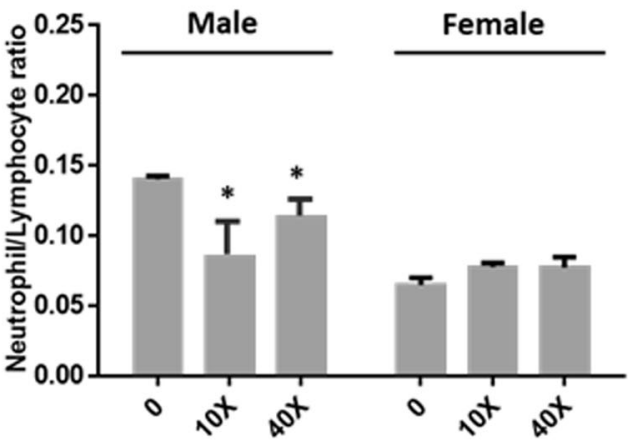

Fig. 1 Acute effect of CAPeo-Changes $24 \mathrm{~h}$ after treatment. The effect of CAPeo on a creatinine (mg/dl), urea (mg/dl), AST(U/L), and ALT(U/L) levels, and $\mathbf{b}$ the neutrophil to lymphocyte ratio was examined $24 \mathrm{~h}$ after treatment. Two different CAPeo doses were tested: $10 \mathrm{X}$ and $40 \mathrm{X}$ of D1 (the human dose adjusted for rat metabolism) both in male $(n=4)$ and female $(n=4)$. The CAPeo doses were given (once) to animals by gavage and blood samples were collected at time 0 and $24 \mathrm{~h}$. Data are represented as mean \pm s.d. Asterisk denotes statistical significance $(t$-test), $p<0.05$

presented in Table 1), it is evident that its most abundant constituents are carvacrol (52\%) and eucalyptol (12\%), with the latter being slightly toxic ( $\mathrm{LD}_{50}: 2480 \mathrm{mg} / \mathrm{kg}^{19}$, category 5). Additionally, for other less abundant constituents of CAPeo such as $p$-cymene ${ }^{19}, \beta$-caryophyllene $e^{20,21}, \gamma$-terpinene $e^{22}$, Borneol $^{23}$ and a-Terpineol ${ }^{24}$, no significant toxicity has been reported $\left(L_{50}\right.$ higher than $2000 \mathrm{mg} / \mathrm{kg}$ body weight), with the exception of aand $\beta$-Thujone which are compounds classified at category 3 $\left(\mathrm{LD}_{50}: 50-300 \mathrm{mg} / \mathrm{kg} \mathrm{bw}\right)^{25,26}$. However, this latter compound is present in very low concentrations in CAPeo $(0.74$ and $0.52 \%$ cisand trans-thujone respectively ${ }^{9}$, making improbable any toxicity considerations, as verified here. Moreover, the aforementioned compounds apart from $\alpha$ - and $\beta$-Thujone are approved by FDA and EFSA for food use (Code for Federal Regulation: 21CFR172.515 and (EU) No 872/2012 of 1 October 2012). While for $a-$ and $\beta$-Thujone an exposure up to $7 \mathrm{mg} /$ day does not pose special concerns $^{27}$.

These data suggest a possible absence of toxicity for CAPeo. However, it was important to evaluate the toxicity of the CAPeo mixture itself especially at a dose range similar to those administered in humans. It is to note, that the registered use of
CAPeo is for one week ( $1 \mathrm{ml} /$ day containing $~ 1.5 \%$ of essential oils mixture).

In the present study, we present evidence that in an acute $(24 \mathrm{~h}$ or 15 days) oral toxicity study CAPeo is indeed not toxic (2 different doses were tested: $10 x$ and $40 x$ of the effective dose in humans, modified as per the animal metabolism ${ }^{28}$. A higher dose could not be tested, due to the nature of CAPeo and the limited volume that can be given to the rat stomach). Similarly, no signs of toxicity were observed in sub-chronic oral administration for 4 months of the effective dose ( $1 x)$, and a $5 x$ and a $20 x$ of this dose, also modified as per the increased rat metabolism. It should be noted that in the case of a beverage with these aromatic plants the doses examined correspond up to 80 and 40 cups per day in the acute and sub-chronic study respectively. All the evaluated parameters (appearance, behavior, complete blood cell count, biochemical and histological) were within the normal range in all doses and time periods examined. Interestingly, the neutrophil to lymphocyte ratio both in the acute and in the sub-chronic study was decreased only in male animals. This is an interesting finding which cannot be attributed to the different male and female growth and food consumption rate since in females no effect was 
a.
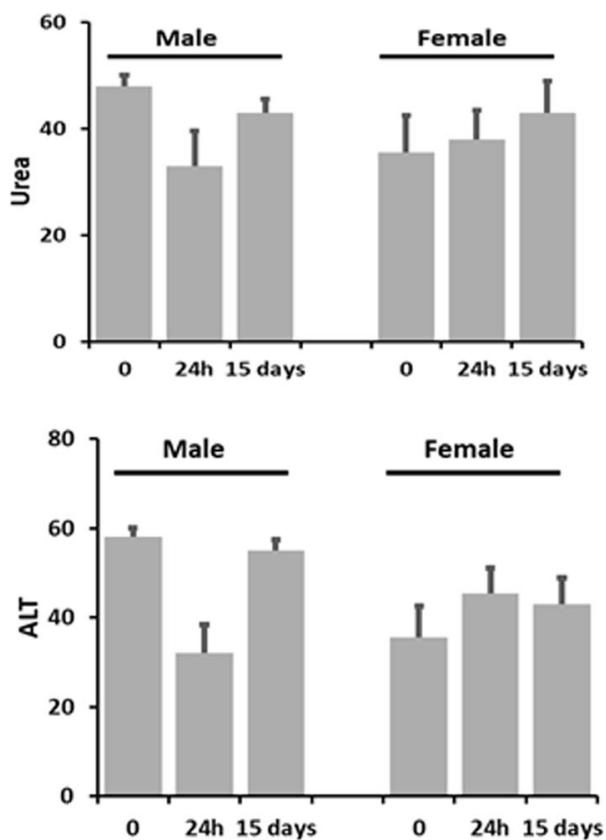

b.

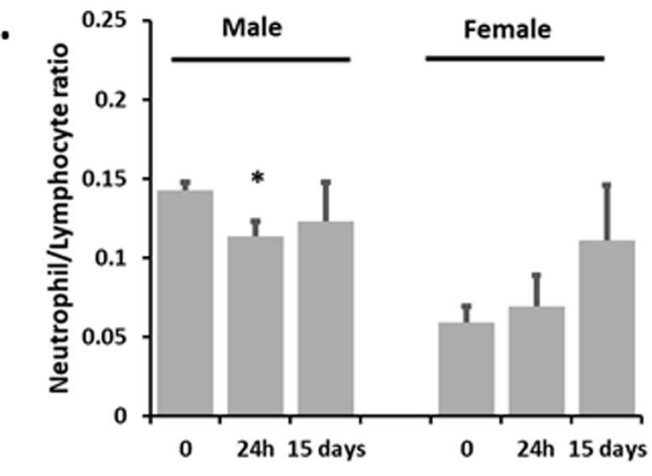

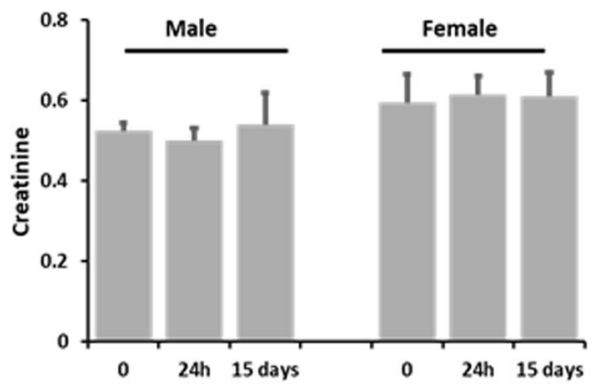

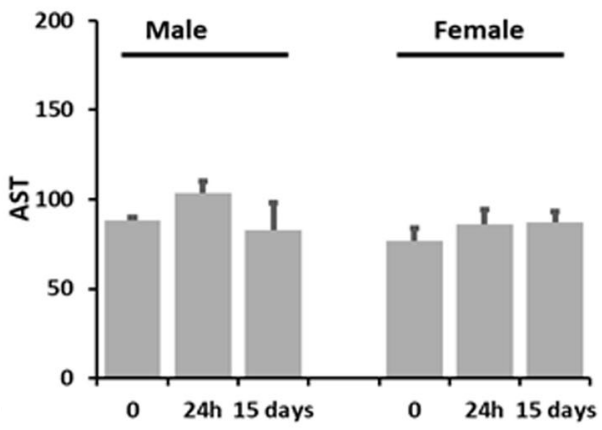

Female

Fig. 2 Acute effect of a high dose of CAPeo -Changes 15 days after treatment. The effect of a high dose of CAPeo on a creatinine (mg/dl), urea $(\mathrm{mg} / \mathrm{dl}), A S T(\mathrm{U} / \mathrm{L})$, and $\mathrm{ALT}(\mathrm{U} / \mathrm{L})$ levels, and $\mathbf{b}$ the neutrophil to lymphocyte ratio was examined 15 days after treatment. The CAPeo dose (40X of D1 the human dose adjusted for rat metabolism) was given (once) to animals ( $n=2 / \mathrm{sex}$ ) by gavage, and blood samples were collected at time 0 and 15 days. Data are represented as mean \pm s.d. Asterisk denotes statistical significance $(t$-test $), p<0.05$.

observed even at the highest dose (corresponding to about 2 times the dose D2 in males, in which dose significant change of the neutrophil to lymphocyte ratio was observed), and points out the possibility for a sex-dependent anti-inflammatory action of CAPeo.

These animal toxicity data greatly support our previous evidence of the absence of short-term toxicity for CAPeo from the double-blind randomized controlled clinical study, where participants received CAPeo for 7 days $^{9,10}$. Analyzing the same hematological and biochemical parameters (Fig. 6) no significant changes in the levels of biochemical markers of liver and kidney toxicity (AST, ALT, creatinine) or the ratio of neutrophils to lymphocytes, as a marker of inflammation, were observed between the intervention and the placebo group.

In conclusion, as scientific evidence of the health effects of herbal beverages is mounting, along with their popularity for daily use, it is important to have a clear and scientifically robust analysis of the safety issues involved. Here we also present, for the first time, the absence of toxicity for Cretan dittany and demonstrate that a mixture of essential oils from Cretan dittany, Greek sage and thyme can be safely utilized.

\section{METHODS}

\section{CAPeo composition}

CAPeo is a mixture of essential oils derived from thyme or Spanish oregano (Coridothymus capitatus (L) Rchb. F. synonym of Thymbra capitata (L) Cav.), dittany or Cretan dittany (Origanum dictamnus L) and Greek sage (Salvia fruticosa Mill.). The extracts were prepared through steam distillation and analyzed by Gas Chromatography-Mass Spectroscopy. A Shimadzu, QP $5050 \mathrm{~A}$ apparatus with an MDN-5 column (length $30 \mathrm{~m}$, film thickness $0.25 \mu \mathrm{m}$, diameter $0.25 \mathrm{~mm}$, max. useable temperature $325^{\circ} \mathrm{C}$ ) and a Quadrupole Mass Spectrometer as detector were used. The temperature of the column was initially $50^{\circ} \mathrm{C}$ for $5 \mathrm{~min}$, gradually increased to $150^{\circ} \mathrm{C}\left(5^{\circ} \mathrm{C} /\right.$ min) for $10 \mathrm{~min}$, and finally increased to $280^{\circ} \mathrm{C}\left(5^{\circ} \mathrm{C} / \mathrm{min}\right)$ and held for $20 \mathrm{~min}$. The carrier gas was helium and the flow rate $0.9 \mathrm{~mL} / \mathrm{min}$. The sample injection volume was $2 \mu \mathrm{L}$ and was measured in a split mode procedure (split ratio 1:35). The temperature for injector and detector was at 230 and $250^{\circ} \mathrm{C}$, respectively. Finally, an electron ionization system (ionization energy at $70 \mathrm{eV}$ ) was utilized for GS-MS detection. The chemical and percentage composition of CAPeo is presented in Table 1. For more details please refer to Supplemental Table 4 of Duijker et al. ${ }^{9}$.

\section{Acute Toxicity Study}

Sprague-Dawley male and female rats (24 weeks old, weighing 300-400 gr), purchased from ENVIGO, were used $(n=4)$. This number of animals attains a statistical significance of at least $p<0.05$, according to the web resource 

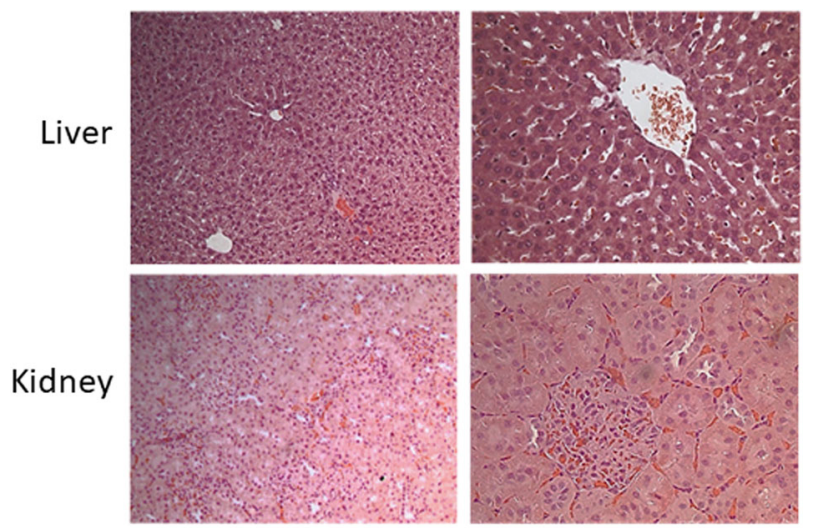

Lung
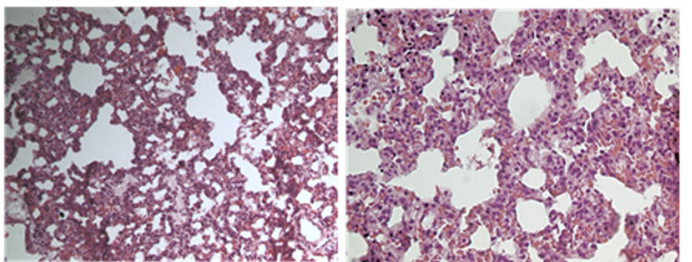

Heart
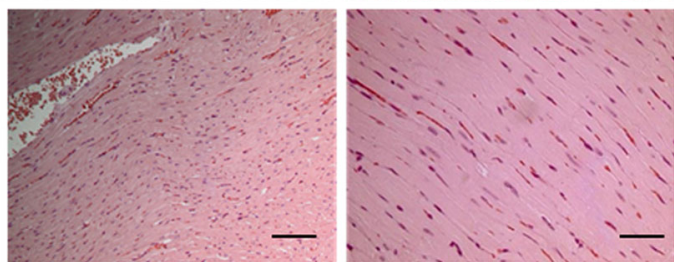

Fig. 3 Study of CAPeo acute toxicity on selected organ tissues. Representative microphotographs of hematoxylin-eosin stained liver, kidney, lung, and heart sections of animals treated with the highest dose (40xD1). Two photos are shown for each tissue one with $\times 200$ and one with $\times 400$ magnification. Scale bar $100 \mu \mathrm{m}$ and $50 \mu \mathrm{m}$ respectively. http://www.biomath.info/power/chsq1gp.htm). In each animal, a single dose of CAPeo essential oils, in a minimal volume of olive oil $(0.25 \mathrm{ml})$ was given by gavage, directly to the stomach. The effect of two different doses was examined (10 and 40 times the corresponding dose of humans, as we have previously tested ${ }^{9}$, adjusted for rat metabolism ${ }^{28}, \mathrm{D} 1: 0.0258 \mathrm{ml}$ of $1.5 \%$ CAPeo in olive oil) both in male and female rats (see Table 2). The study was conducted according to the OECD guidelines for testing acute oral toxicity ${ }^{29}$. Higher doses could not be tested, due to the limitation of the volume of CAPeo (which is a mixture of essential oils in oil) that could be given to the limited volume of the rat stomach, in a single dose. The animals were single caged, had unlimited access to food and water and were kept under normal laboratory conditions. They were closely monitored for $24 \mathrm{~h}$ and blood samples were collected at different time points $(2,6$ and $24 \mathrm{~h})$ for complete blood cell counting, and biochemical analysis. Additionally, animals (male and female, $n=2 /$ sex) treated by gavage with the highest dose (40 times D1) were closely monitored for 15 days and blood samples and tissues were collected at the end of the observational period.

After $24 \mathrm{~h}$ or 15 days animals were sacrificed, all organs were evaluated and selected tissues (kidney, liver, lungs and heart) were formalin-fixed and a detailed histological analysis was performed, for signs of inflammation, histological changes or necrosis, after Hematoxylin-Eosin staining.

\section{Sub-chronic Toxicity Study}

Male and female Sprague-Dawley rats (8 weeks old, weighting 200-300 gr) were purchased from ENVIGO. Animals were caged in groups of 4-5 rats, had unlimited access to food and water and were kept under normal laboratory conditions. The study was conducted based on the OECD guidelines for testing sub-chronic oral toxicity ${ }^{30}$. Based on previous toxicity data for some of the CAPeo constituents, no toxicity and deaths were expected and therefore (taking also in to account the 3Rs for animal welfare) 10 animals per group were used in order to attain statistical significance of at least $p<0.05$, according to the web resource http://www. biomath.info/power/ttest.htm). Animals were randomly assigned in 5 study groups for each gender separately (see Table 3): 1) No treatment group: normal diet, D0 2) D1 group: $0.0258 \mathrm{ml}$ of $1.5 \%$ CAPeo in olive oil/day, the dose administered to humans adjusted for rat metabolism, 3) D2 group: 5 times Dose 1, 4) D3 group: 20 times Dose 1,5) D4 group: Olive oil-Only treatment (vehicle). Due to the nature of CAPeo mixture a higher dose could not be administered.
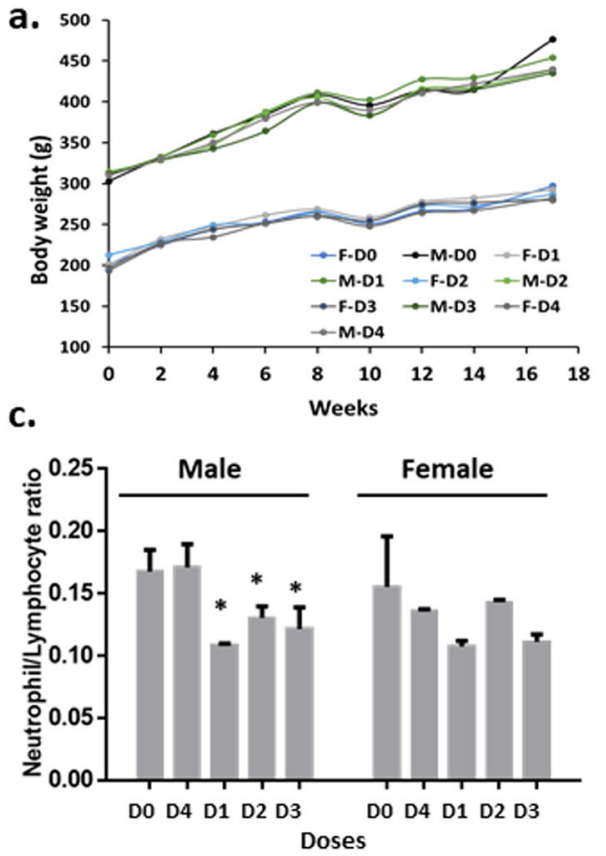

b.
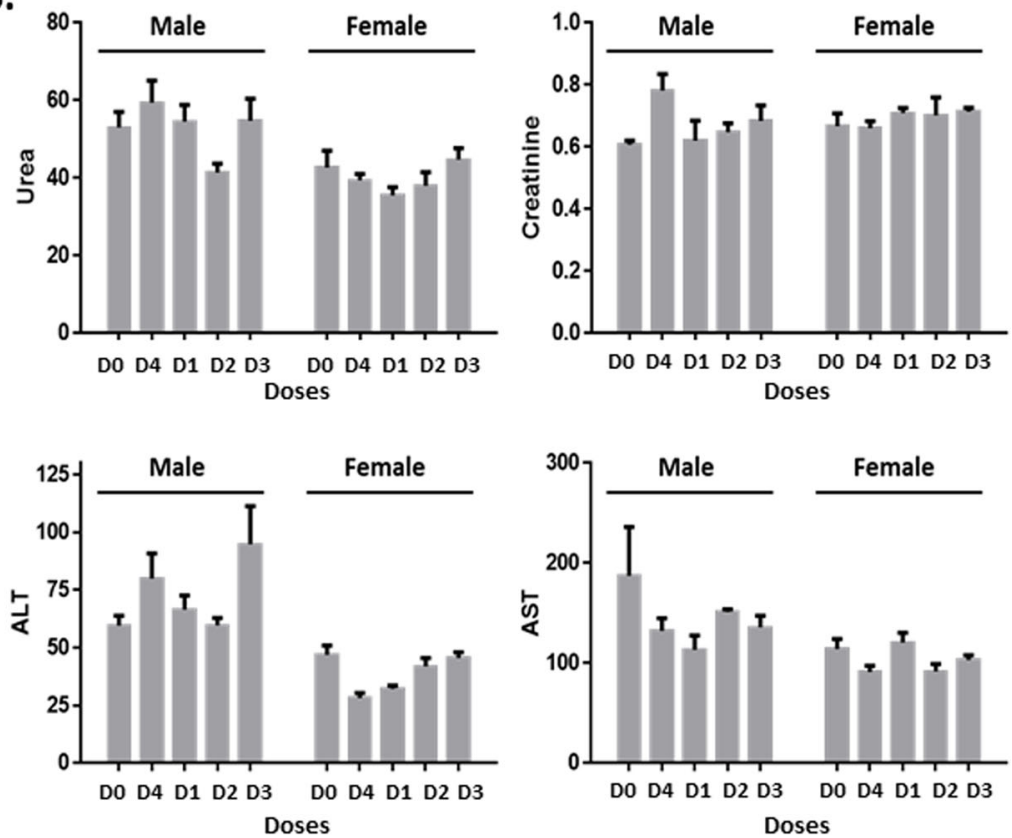

Fig. 4 Sub-chronic effect of CAPeo. Sub-chronic CAPeo effect on a Body weight of the animals (M- denotes male and F- female) $\mathbf{b}$ creatinine $(\mathrm{mg} / \mathrm{dl})$, urea $(\mathrm{mg} / \mathrm{dl}), A S T(\mathrm{U} / \mathrm{L})$, and $\mathrm{ALT}(\mathrm{U} / \mathrm{L})$ levels, and $\mathbf{c}$ the neutrophil to lymphocyte ratio was examined. The effect of the three different CAPeo doses (D1, the human dose adjusted for rat metabolism see Methods for more details), D2: 5xD1 and D3: 20xD1) after 4 months of treatment, along with only olive oil (the vehicle-D4) and untreated animals (D0) is presented separately in male $(n=5)$ and female $(n=5)$. Data are represented as mean \pm s.d. Asterisk denotes statistical significance $(t$-test), $p<0.05$. 

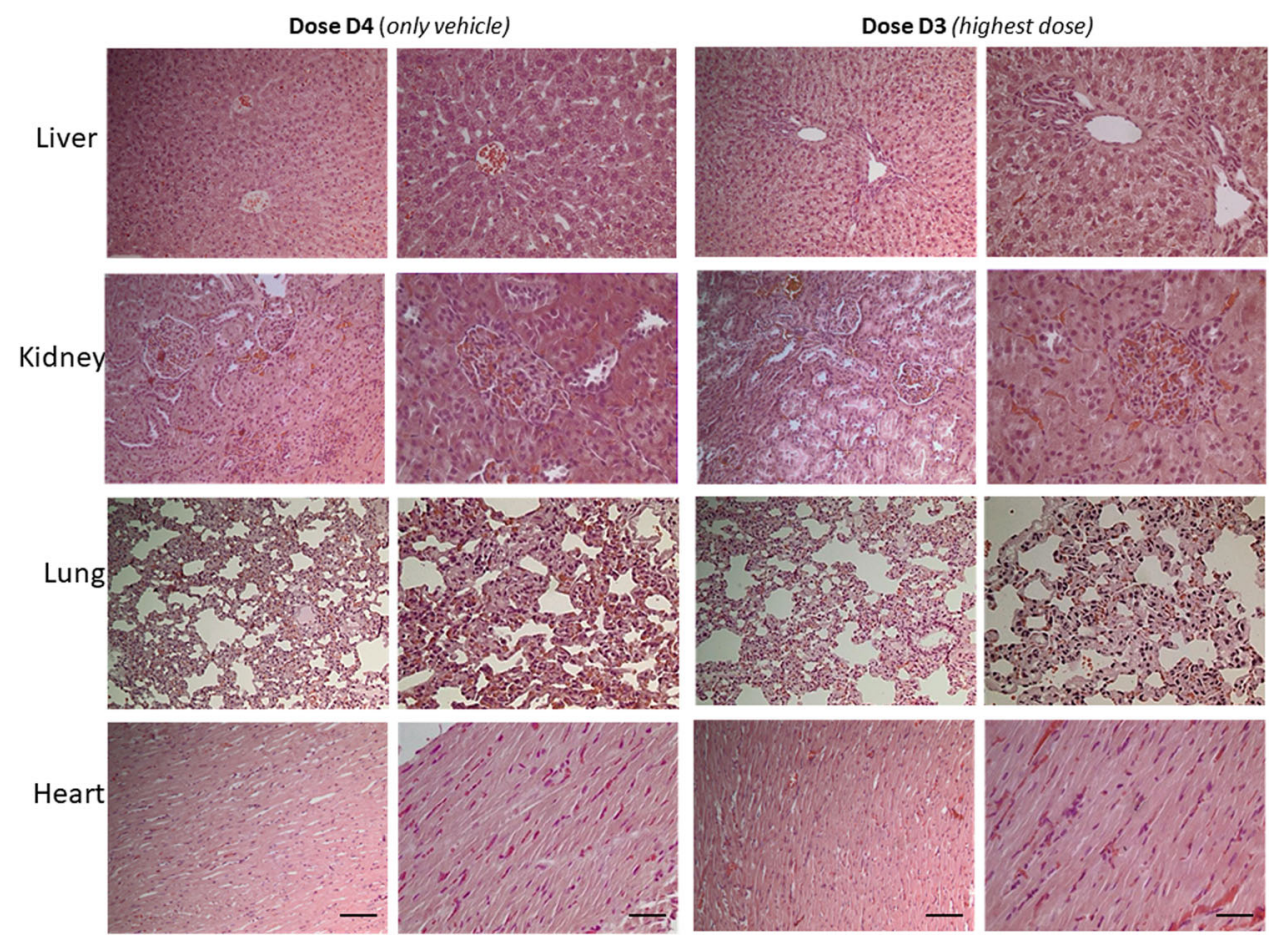

Fig. 5 Study of CAPeo sub-chronic toxicity on selected organ tissues. Representative microphotographs of hematoxylin-eosin stained liver, kidney, lung, and heart sections of animals from the highest dose group (D3) and the only vehicle group (D4). Two photos are shown for each group and each tissue one with $\times 200$ and one with $\times 400$ magnification. Scale bar $100 \mu \mathrm{m}$ and $50 \mu \mathrm{m}$ respectively.

\begin{tabular}{|c|c|c|}
\hline No & Compound & Percentage (\%) composition \\
\hline 1 & $\beta$-Myrcene & 0.21 \\
\hline 2 & p-Cymene & 1.32 \\
\hline 3 & Eucalyptol & 12.77 \\
\hline 4 & $\gamma$-Terpinene & 1.17 \\
\hline 5 & cis-Sabinene hydrate & 0.45 \\
\hline 6 & trans-Sabinenhydrate & 0.22 \\
\hline 7 & Linalool & 0.71 \\
\hline 8 & cis-Thujone & 0.74 \\
\hline 9 & trans-Thujone & 0.52 \\
\hline 10 & Camphor & 0.81 \\
\hline 11 & $\delta$-Terpineol & 0.35 \\
\hline 12 & Borneol & 1.68 \\
\hline 13 & Terpinen-4-ol & 0.61 \\
\hline 14 & $\alpha$-Terpineol & 1.06 \\
\hline 15 & Thymol & 0.43 \\
\hline 16 & Carvacrol & 52.57 \\
\hline 17 & $\delta$-Terpinyl acetate & 0.35 \\
\hline 18 & $\beta$-Caryophyllene & 3.41 \\
\hline 19 & $\alpha$-Caryophyllene & 0.3 \\
\hline 20 & Methylparaben & 2.91 \\
\hline 21 & Caryophyllene oxide & 0.45 \\
\hline 22 & Viridiflorol & 0.23 \\
\hline 23 & $\mathrm{n}$-Hexadecanoic acid & 0.82 \\
\hline 24 & Oleic Acid & 11.41 \\
\hline 25 & Squalene & 4.15 \\
\hline
\end{tabular}

${ }^{\mathrm{a}}$ Table was extracted from data presented in reference ${ }^{9}$.
All animal diets were in a paste form so that olive oil and CAPeo dose could be better incorporated. All doses (see Table 3) were given adjusted in $15 \mathrm{ml}$ olive oil/Kg diet. Rats were kept on these diets for 4 months. During this period, animals were closely monitored, and their food consumption and weight was recorded weekly. At the start and at the end of the study, blood samples were collected. After 4 months, animals were sacrificed, all organs were evaluated and selected tissues (kidney, liver, lungs and heart) were formalin-fixed and a detailed histological analysis was performed by two independent trained pathologists, for signs of inflammation, histological changes or necrosis, after Hematoxylin-Eosin staining.

\section{Ethics}

Both studies were approved by the University of Crete, School of Medicine Committee for animal welfare (Protocol no. 276957) and all experiments were performed in accordance with relevant guidelines and regulations.

\section{Macroscopic evaluation}

Animals in both studies were closely observed for mortality and any visible signs of morbidity and mortality along with changes in behavior and physiological function. More specifically according to Irwin test, their mood, perception, motor activity, and central nervous system excitation were assessed ${ }^{31}$. In parallel any signs of depression, salivation, diarrhea and any skin, fur and eye mucosa changes were recorded.

\section{Blood sample analysis}

During the studies and at the end, blood samples were collected, (from rat tail vein and cardiac puncture respectively). Blood was collected in an EDTA-containing tube, gently inversed and analyzed within 2 hours after collection, for complete blood cell counting. For biochemical analysis, blood was centrifuged and serum samples were either analyzed within 3 hours or aliquoted and kept at $-80^{\circ} \mathrm{C}$.

Complete blood cell count was performed at the University Hospital of Heraklion, Laboratory of Haematology, in Beckman-Coulter DxH600 CBC analyzer (Beckman-Coulter, CA, USA) analyzer, according to standard operating procedures. 

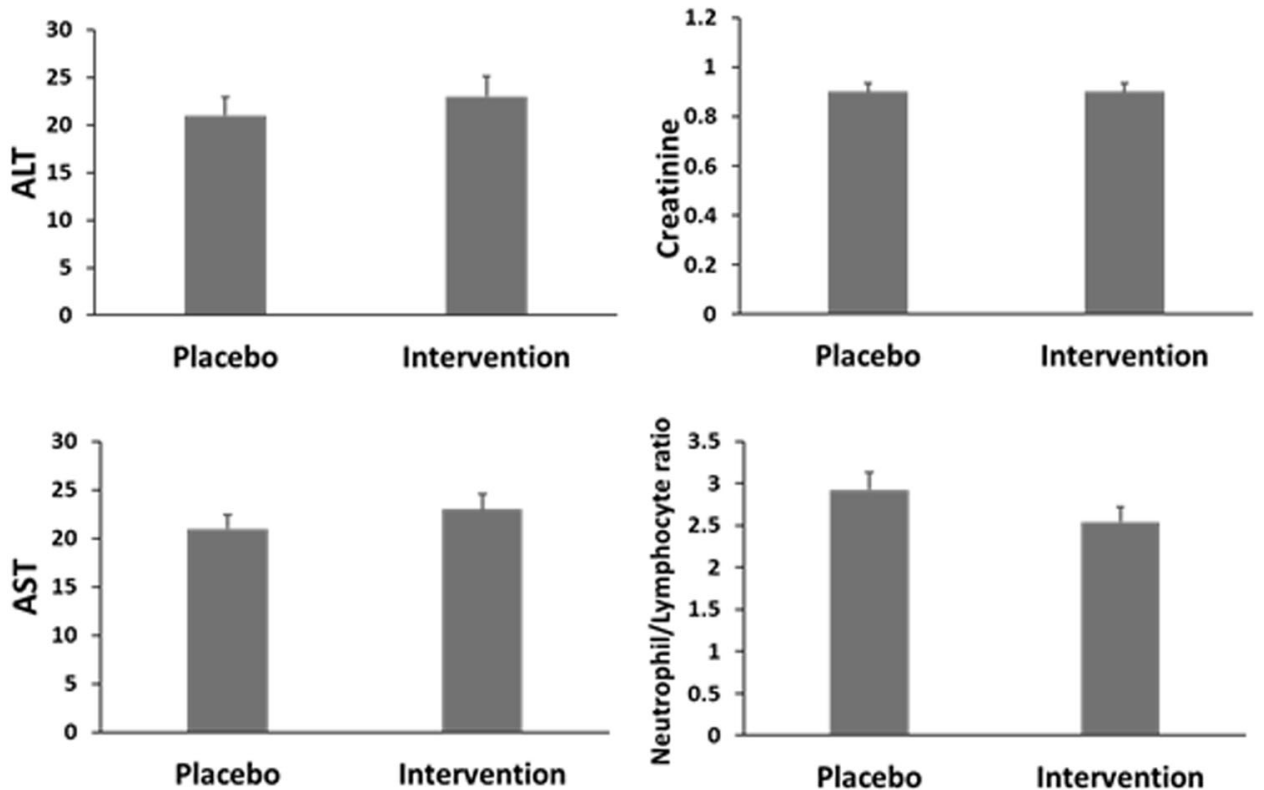

Fig. 6 Effect of CAPeo on human biochemical parameters. CAPeo effect on creatinine (mg/dl), AST(U/L), ALT(U/L) levels, and the neutrophil to lymphocyte ratio after 7 days of intervention is presented. Analysis of data reported in Supplemental Table 6 of Duijker et al. ${ }^{9}$.

\begin{tabular}{|lll|}
\hline Table 2. & Animal numbers and doses in Acute Toxicity Study at 24 h. \\
\hline Gender & Number of animals & Dose \\
\hline Male & 4 & 0 (only oil) \\
& 4 & $10 x \mathrm{D} 1$ \\
& 4 & $40 x \mathrm{D} 1$ \\
Female & 4 & 0 (only oil) \\
& 4 & $10 x \mathrm{D} 1$ \\
& 4 & $40 x \mathrm{D} 1$ \\
\hline
\end{tabular}

D1 $0.0258 \mathrm{ml}$ CAPeo (conc: $1,5 \%$ in extra virgin olive oil).

Table 3. Animal numbers and doses in Sub-chronic Toxicity Study.

\begin{tabular}{llll}
\hline Group & Gender & Animal number & Dose \\
\hline D0 & Male & 5 & 0 (No treatment) \\
& Female & 5 & \\
D1 & Male & 5 & D1 \\
& Female & 5 & $5 \times$ D1 \\
D2 & Male & 5 & \\
& Female & 5 & $20 \times$ D1 \\
D3 & Male & 5 & OO (only oil) \\
& Female & 5 & \\
D4 & Male & 5 & \\
& Female & 5 & \\
\hline D1 $0.0258 \mathrm{ml}$ CAPeo/animal /day (conc: $1.5 \%$ in extra virgin olive oil).
\end{tabular}

Biochemical markers. All biochemical parameters (glucose, triglycerides, total cholesterol, LDL cholesterol, HDL cholesterol, hs-CRP, urea, creatinine, YGT, SGOT, and SGPT) were measured using Olympus AU2700 Analyzer at the Laboratories of Biochemistry and Clinical Immunology of the University Hospital of Heraklion.
Pathology

For each animal a detailed gross necropsy was conducted. This included careful examination of the external surface of the body, all orifices, and the cranial, thoracic and abdominal cavities and their contents.

All organs were examined macroscopically and tissue samples were formalin-fixed (10\%) and embedded in paraffin. In selected organs (liver, kidney, heart and lung), for all animals in the study groups, any signs of necrosis, injury or inflammation were assessed using hematoxylin-eosin staining. Histological analysis and evaluation were estimated by two independent pathologists.

Statistical analysis

Statistical analysis (t-test, ANOVA, as appropriate) was performed by the GraphPad Prism V 6.0.

\section{DATA AVAILABILITY}

The authors declare that all data supporting the findings of this study are available within the paper. Raw data that support the findings of this study are available from the corresponding author upon reasonable request.

Received: 18 February 2020; Accepted: 12 October 2020; Published online: 09 November 2020

\section{REFERENCES}

1. Pandey, K. B. \& Rizvi, S. I. Plant polyphenols as dietary antioxidants in human health and disease. Oxid. Med. Cell. Longev. 2, 270-278 (2009).

2. Vauzour, D., Rodriguez-Mateos, A., Corona, G., Oruna-Concha, M. J. \& Spencer, J. P. Polyphenols and human health: prevention of disease and mechanisms of action. Nutrients 2, 1106-1131 (2010).

3. Cory, H., Passarelli, S., Szeto, J., Tamez, M. \& Mattei, J. The role of polyphenols in human health and food systems: a mini-review. Front. Nutr. 5, 87 (2018).

4. Salehi, B. Le Regime Sante (Editions Odile Jacob, Paris, 1995).

5. Lionis, C., Faresjo, A., Skoula, M., Kapsokefalou, M. \& Faresjo, T. Antioxidant effects of herbs in Crete. Lancet 352, 1987-1988 (1998).

6. Lindholm, L. H. et al. Risk factors for ischaemic heart disease in a Greek population. A cross-sectional study of men and women living in the village of Spili in Crete. Eur. Heart J. 13, 291-298 (1992).

7. Lionis, C. D. et al. Mortality rates in a cardiovascular 'low-risk' population in rural Crete. Fam. Pract. 10, 300-304 (1993). 
8. Tseliou, M., Pirintsos, S. A., Lionis, C., Castanas, E. \& Sourvinos, G. Antiviral effect of an essential oil combination derived from three aromatic plants (Coridothymus capitatus (L.) Rchb. f., Origanum dictamnus L. and Salvia fruticosa Mill.) against viruses causing infections of the upper respiratory tract. J. Herb. Med. 17-18, 100288-100295 (2019).

9. Duijker, G. et al. Reporting effectiveness of an extract of three traditional Cretan herbs on upper respiratory tract infection: results from a double-blind randomized controlled trial. J. Ethnopharmacol. 163, 157-166 (2015).

10. Anastasaki, M., Bertsias, A., Pirintsos, S. A., Castanas, E. \& Lionis, C. Post-market outcome of an extract of traditional Cretan herbs on upper respiratory tract infections: a pragmatic, prospective observational study. BMC Complement. Altern. Med. 17, 466 (2017).

11. Salehi, B. et al. Thymol, thyme, and other plant sources: Health and potential uses. Phytother. Res. 32, 1688-1706 (2018).

12. Rojas-Armas, J. et al. Acute and repeated 28-day oral dose toxicity studies of thymus vulgaris L. essential oil in rats. Toxicol. Res. 35, 225-232 (2019).

13. EFSA, Conclusion on the peer review of the pesticide risk assessment of the active substance thymol. EFSA J. 10, 1-43 (2012).

14. Mills, S. \& Kerry, B. The Essential Guide to Herbal Safety (Elsevier, St Louis, Missouri, 2005).

15. Eidi, M., Eidi, A. \& Zamanizadeh, H. Effect of Salvia officinalis L. leaves on serum glucose and insulin in healthy and streptozotocin-induced diabetic rats. J. Ethnopharmacol. 100, 310-313 (2005).

16. Basch, E., Ulbricht, C., Hammerness, P., Bevins, A. \& Sollars, D. Thyme (Thymus vulgaris L.), thymol. J. Herb. Pharmacother. 4, 49-67 (2004).

17. Ghorbani, A. \& Esmaeilizadeh, M. Pharmacological properties of Salvia officinalis and its components. J. Tradit. Complement. Med. 7, 433-440 (2017).

18. Ghorani, V., Alavinezhad, A., Rajabi, O., Mohammadpour, A. H. \& Boskabady, M. H. Safety and tolerability of carvacrol in healthy subjects: a phase I clinical study. Drug Chem. Toxicol. Nov 29, 1-12 (2018).

19. Jenner, P. M., Hagan, E. C., Taylor, J. M., Cook, E. L. \& Fitzhugh, O. G. Food flavourings and compounds of related structure. I. Acute oral toxicity. Food Cosmet. Toxicol. 2, 327-343 (1964).

20. Oliveira, G. et al. Non-clinical toxicity of beta-caryophyllene, a dietary cannabinoid: absence of adverse effects in female Swiss mice. Regul. Toxicol. Pharmacol. 92, 338-346 (2018).

21. Schmitt, D., Levy, R. \& Carroll, B. Toxicological evaluation of beta-caryophyllene oil: subchronic toxicity in rats. Int. J. Toxicol. 35, 558-567 (2016).

22. Passos, F. F. et al. Involvement of cholinergic and opioid system in gammaterpinene-mediated antinociception. Evid. Based Complement. Alternat. Med. 2015, 829414 (2015).

23. Horikawa, E. \& Okada, T. [Experimental study on acute toxicity of phenol camphor (author's transl)]. Shikwa Gakuho 75, 934-939 (1975).

24. Letizia, C. S., Cocchiara, J., Lalko, J. \& Api, A. M. Fragrance material review on linalyl acetate. Food Chem. Toxicol. 41, 965-976 (2003).

25. Rice, K. C. \& Wilson, R. S. (-)-3-Isothujone, a small nonnitrogenous molecule with antinociceptive activity in mice. J. Med. Chem. 19, 1054-1057 (1976).

26. Waidyanatha, S. et al. Toxicokinetics of alpha-thujone following intravenous and gavage administration of alpha-thujone or alpha- and beta-thujone mixture in male and female F344/N rats and B6C3F1 mice. Toxicol. Appl. Pharmacol. 271, 216-228 (2013).

27. Committee on Herbal Medicinal Products (HMPC). Assessment report on Salvia officinalis L., folium and Salvia officinalis L., aetheroleum. EMA/HMPC/150801/ 2015 (European Medicines Agency (EMA), 2017).

28. Reagan-Shaw, S., Nihal, M. \& Ahmad, N. Dose translation from animal to human studies revisited. FASEB J. 22, 659-661 (2008).
29. Organisation for Economic Cooperation and Development (OECD). OECD Guideline for the Testing of Chemicals Test No. 420: Acute Oral Toxicity - Fixed Dose Procedure. OECDiLibrary, 1-14 (2001).

30. Organisation for Economic Cooperation and Development (OECD). OECD Guideline for the Testing of Chemicals Test No. 408: Repeated Dose 90-Day Oral Toxicity Study in Rodents. OECDiLibrary (2018).

31. Roux, S., Sable, E. \& Porsolt, R. D. Primary observation (Irwin) test in rodents for assessing acute toxicity of a test agent and its effects on behavior and physiological function. Curr. Protoc. Pharmacol. 10, 1-23 (2005).

\section{ACKNOWLEDGEMENTS}

This work was supported by a grant from OLVOS Pharmaceuticals. We would like to thank Dr Pavlina Tsoka for her help with the animals.

\section{AUTHOR CONTRIBUTIONS}

MK, EC, SP, CL, SG conceived and designed the study, KK, PM, NM, IM, RV, GN, NM, EM MT performed the analyses and experiments, $\mathrm{SP}, \mathrm{CL}$, SG participated in the analysis of experimental data, MK, EC, wrote the paper, and all authors read and approved the final manuscript.

\section{COMPETING INTERESTS}

SP, CL and EC are inventors of a patent (WO2010GB01836 20100929 and additional national related patents) on the use of the three aromatic plants against upper respiratory tract infections. The other authors have nothing to declare.

\section{ADDITIONAL INFORMATION}

Correspondence and requests for materials should be addressed to M.K.

Reprints and permission information is available at http://www.nature.com/ reprints

Publisher's note Springer Nature remains neutral with regard to jurisdictional claims in published maps and institutional affiliations.

Open Access This article is licensed under a Creative Commons Attribution 4.0 International License, which permits use, sharing, adaptation, distribution and reproduction in any medium or format, as long as you give appropriate credit to the original author(s) and the source, provide a link to the Creative Commons license, and indicate if changes were made. The images or other third party material in this article are included in the article's Creative Commons license, unless indicated otherwise in a credit line to the material. If material is not included in the article's Creative Commons license and your intended use is not permitted by statutory regulation or exceeds the permitted use, you will need to obtain permission directly from the copyright holder. To view a copy of this license, visit http://creativecommons. org/licenses/by/4.0/.

(c) The Author(s) 2020 